Endocrinol. Japon. 1970, 17 (6), 441 446

\title{
Initiation of Milk Secretion in the Male Rat by Single Injections of Reserpine
}

\author{
Yasumasa ARAI, Akio KUBOKURA*, YoshiHide SUZUKI \\ AND SAKAE MASUDA \\ Departments of Anatomy and Neuropsychiatry*, \\ Juntendo University School of Medicine, Hongo, Tokyo
}

\begin{abstract}
Synopsis
Mammary gland development and secretion in male rats were induced by single injections of reserpine. The lactogenic effect of reserpine was most marked when a dose of $1 \mathrm{mg} / \mathrm{kg}$ was given. The alveoli and ducts of the male mammary glands were greatly distended with milky secretion. Similar changes in the glands were also observed but in a smaller number of animals when a dose of $0.5-0.75 \mathrm{mg} / \mathrm{kg}$ was given. Nialamide (250 $\mathrm{mg} / \mathrm{kg})$ counteracted the effect of reserpine $(1 \mathrm{mg} / \mathrm{kg})$ when given $16-18$ hours before the reserpine injection. A similar inhibition was obtained by L-DOPA $(250 \mathrm{mg} / \mathrm{kg})$ when injected one hour after the reserpine injection. These results provide the evidence that the male pituitary is capable of secreting prolactin in response to reserpine, and also suggest the involvement of monoaminergic mechanisms in the process of prolactin release in the male rat.
\end{abstract}

Galactorrhea has been reported to occur frequently in female mammals and patients given reserpine and certain neuroleptic drugs (Wilkins, 1954; Robinson, 1957; Meites, 1962). Since central regulation of prolactin secretion is of inhibitory nature in females and mediated via hypothalamic prolactin inhibiting factor (PIF), the depressing action of reserpine and certain neuroleptics on the CNS, presumably on the hypothalamus, is thought to be the basis for the effect on prolactin release (Meites, 1966; Everett, 1966; Gold and Ganong, 1967; Kanematsu, 1968). Ratner et al. (1965) recently suggested that reserpine produces this effect by directly suppressing the production and release of the PIF of the hypothalamus.

There is evidence suggesting that depletion of neuronal monoamine stores by reserpine would be related to the suppression of the synthesis and/or release of the PIF in the hypothalamus. Coppola et al. (1965) reported

Received for publication November 24, 1970. that pseudopregnancy could be induced by brain monoamine depletors such as reserpine, $\alpha$-methyl-DOPA and tetrabenazine, while this effect could be reversed by the treatment with L-DOPA or a monoamine oxidase (MAO) inhibitor. This is also in agreement with the findings that a MAO-inhibitor suppressed lactation in rats (Mizuno et al., 1964).

Little is known of the functional significance and control mechanisms of prolactin secretion in the male, although prolactin secretion in the male rat has been demonstrated under certain conditions (Zeilmaker, 1963; De Voe et al., 1965; Deis, 1967). With respect to the effect of reserpine, the possibility that the male pituitary is capable of secreting prolactin has been suggested by Zeilmaker (1963). He showed that copora lutea (induced by HCG) in the ovarian transplants became functional in the castrated male rats following daily administration of reserpine. Recently we found that single injections of reserpine induced lobulo-alveolar development and milk secretion in the mammary gland of male rats. 
In the experiments to be reported here possible pharmacologic mechanisms by which reserpine might cause prolactin secretion in the male rat were studied.

\section{Materials and Methods}

Adult male rats of the Wistar strain (180-230 g) purchased from Fuji Animal Farm were used in the present experiments. The animals were maintained in group cages and given free access to a standard rat pellet diet and water. Drugs except nialamide* were dissolved or suspended in a special reserpine placebo** and injected subcutaneously. In a preliminary series of experiments, a single injection of graded doses of reserpine $(0.1-1.0 \mathrm{mg} / \mathrm{kg})$ was given. In order to overcome the effect of reserpine $(1 \mathrm{mg} / \mathrm{kg})$, nialamide- $\mathrm{HCl}$ $(250 \mathrm{mg} / \mathrm{kg}$ ) was given 16-18 hours before the injection of reserpine. Other animals were given L-DOPA (250 $\mathrm{mg} / \mathrm{kg}$ ) one hour after the reserpine injection for the same purpose. The animals treated with nialamide, L-DOPA or the placebo alone, respectively and normal males were served as controls. Two days after the injection of reserpine the animals were sacrificed. The inguinal mammary pads were fixed in Bouin's fluid and the serial sections cut at $10 \mu$ in paraffin were stained with $\mathrm{H}-\mathrm{E}$. The evaluation of lactogenic effect on the mammary gland of each rat was made accord-

* Dissolved in distilled water.

** This placebo was prepared by the Torii Pharmaceutical Co. for their Triserpine brand of reserpine. ing to the scales shown in Figure 1 and Table 1. At autopsy weights of the body, the pituitary, testes and adrenals were recorded per rat.

\section{Results}

Table 1 summarized the results of the lactogenic effect of single injections of graded doses of reserpine. A dose of $1 \mathrm{mg} / \mathrm{kg}$ produced a marked lobulo-alveolar development in the mammary glands. Milky secretion was found macroscopically in 7 out of 10 rats and microscopically in the remaining 3 . On microscopic examination, the alveoli and ducts of all rats were greatly distended with milky secretion and most of them resembled the lactating type (see, Fig. 1-V). Similar histological changes both in the alveoli and the duct system were also obtained with doses of $0.75 \mathrm{mg} / \mathrm{kg}$ and $0.5 \mathrm{mg} / \mathrm{kg}$, but only limited to 4 out of 6 and 5 out of 10 rats (Fig. 1-IV), respectively. When doses of $0.25 \mathrm{mg} / \mathrm{kg}$ and $0.1 \mathrm{mg} / \mathrm{kg}$ were given, the alveolar distention with milky secretion which occurred in the rats treated with doses larger than $0.5 \mathrm{mg} / \mathrm{kg}$ was not found. The only change observed in these rats were a slight enlargement of the alveoli and ducts of the glands (Fig. 1-II and

Table 1. Effect of single injections of graded doses of reserpine on the mammary gland

\begin{tabular}{|c|c|c|c|c|c|c|c|c|c|c|c|c|c|c|}
\hline \multirow{3}{*}{$\begin{array}{c}\text { Dose } \\
(\mathrm{mg} / \mathrm{kg})\end{array}$} & \multirow{3}{*}{$\begin{array}{l}\text { No. of } \\
\text { rats }\end{array}$} & \multirow{3}{*}{$\begin{array}{l}\text { Body } \\
\text { weight } \\
\text { (g) }\end{array}$} & \multicolumn{3}{|c|}{ Organ weight } & \multicolumn{9}{|c|}{ Mammary response* } \\
\hline & & & \multirow{2}{*}{$\begin{array}{l}\text { Pituitary } \\
\text { (mg) }\end{array}$} & \multirow{2}{*}{$\begin{array}{l}\text { Adrenals } \\
\text { (mg) }\end{array}$} & \multirow{2}{*}{$\begin{array}{c}\text { Testes } \\
\text { (g) }\end{array}$} & \multicolumn{4}{|c|}{ Duct system } & \multicolumn{5}{|c|}{ Alveolar system } \\
\hline & & & & & & & & & & I & & III & & $\mathrm{V}$ \\
\hline $0.0 * *$ & 10 & $215 \pm 15 * * *$ & $10.8 \pm 0.6$ & $44.0 \pm 1.6$ & $2.4 \pm 0.2$ & 7 & 2 & 1 & 0 & 5 & 3 & 1 & 1 & 0 \\
\hline 0.1 & 5 & $201 \pm 10$ & $10.6 \pm 0.5$ & $43.5 \pm 3.0$ & $2.7 \pm 0.2$ & 1 & 3 & 1 & 0 & 1 & 3 & 1 & 0 & 0 \\
\hline 0.25 & 5 & $206 \pm 15$ & $10.0 \pm 0.7$ & $47.6 \pm 2.3$ & $2.0 \pm 0.5$ & 0 & 4 & 1 & 0 & 0 & 3 & 2 & 0 & 0 \\
\hline 0.5 & 10 & $202 \pm 6$ & $9.8 \pm 0.6$ & $51.4 \pm 3.6$ & $2.2 \pm 0.2$ & 1 & 2 & 2 & 5 & 1 & 0 & 4 & 3 & 2 \\
\hline 0.75 & 6 & $210 \pm 16$ & $10.1 \pm 0.6$ & $51.0 \pm 4.1$ & $2.1 \pm 0.2$ & 0 & 0 & 2 & 4 & 0 & 0 & 2 & 2 & 2 \\
\hline 1.0 & 10 & $213 \pm 11$ & $10.9 \pm 0.6$ & $50.8 \pm 1.6$ & $2.2 \pm 0.3$ & 0 & 0 & & 10 & 0 & 0 & 0 & 3 & 7 \\
\hline No placebo & 6 & $218 \pm 11$ & $10.3 \pm 0.3$ & $42.6 \pm 2.4$ & $2.3 \pm 0.5$ & 6 & 0 & 0 & 0 & 4 & 2 & 0 & 0 & 0 \\
\hline
\end{tabular}

*Ratings for duct system; - , small, no epithelial proliferation; \pm , multiplication of the ducts, but no secretion; + , increased proliferation of the duct epithelium; + , increased epithelial proliferation and abundant secretion in the duct. For alveolar system, see Figure $1 \mathrm{I}-\mathrm{V}$. Grades IV and V characterized by the high distention of alveoli with milky secretion were defined as positive lactogenic response in the present investigation.

**Injected with special reserpine placebo alone. $\quad * * *$ Mean $\pm \mathrm{SE}$ 


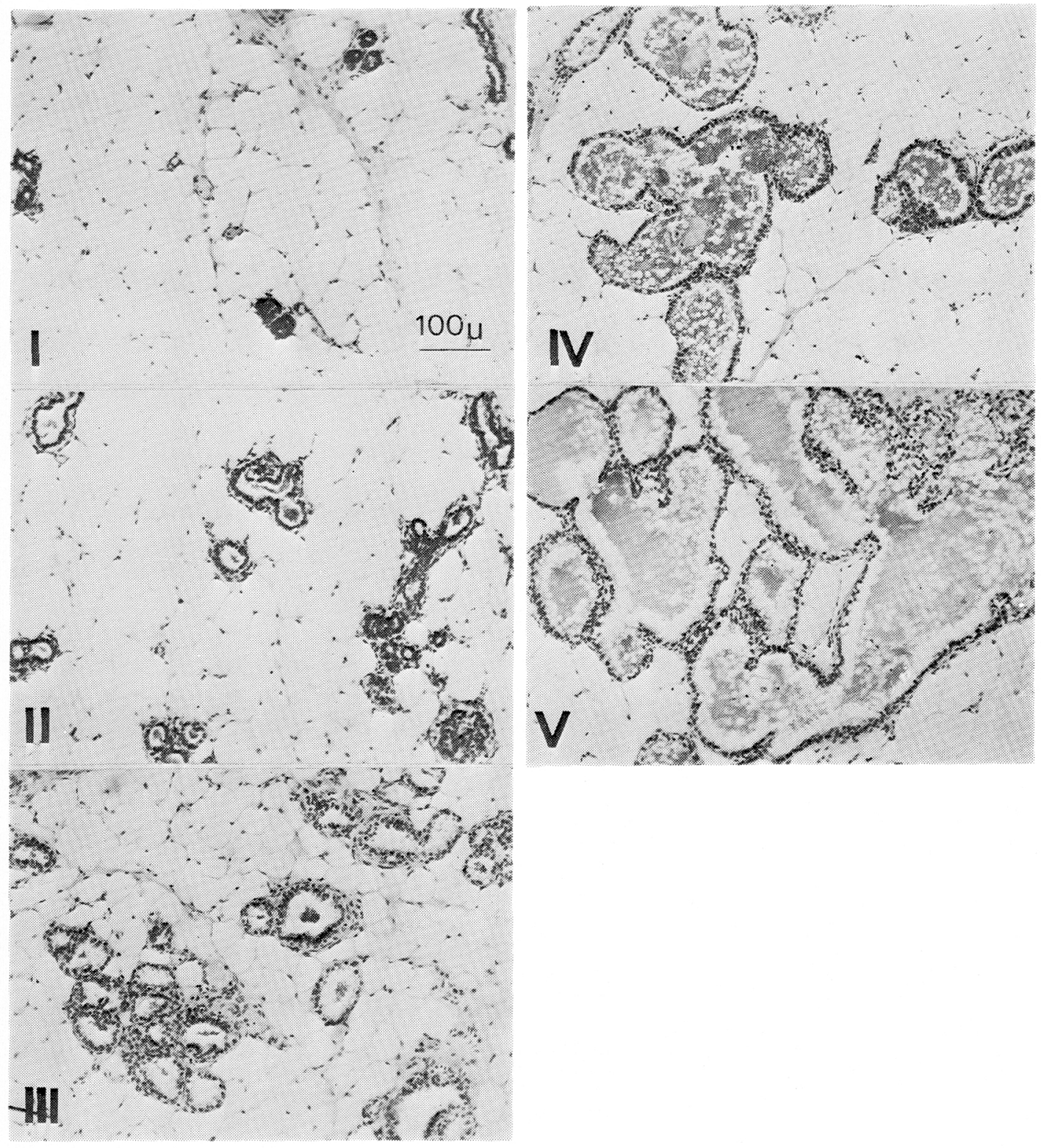

Fig. 1. Histological criteria for the responses of the male mammary gland to reserpine. (I), End buds or small alveoli without secretion (mammary gland of a male rat treated with reserpine placebo alone); (II), Small alveoli with secretion (mammary gland of a male rat treated with a dose of $0.1 \mathrm{mg} / \mathrm{kg}$, reserpine); (III), Slight enlargement of alveolar size with secretion (mammary gland of a rat given reserpine, 0.25 $\mathrm{mg} / \mathrm{kg}$ ); (IV), Distended alveoli with milky secretion (mammary gland of a rat given reserpine, $0.5 \mathrm{mg} / \mathrm{kg}$ ); (V), Greatly distended alveoli with milky secretion throughout sections (mammary gland of a rat treated with a dose of $1 \mathrm{mg} / \mathrm{kg}$, reserpine). 
Table 2. Effect of reserpine in combination with nialamide or L-DOPA on the male mammary gland

\begin{tabular}{|c|c|c|c|c|c|c|c|c|c|c|}
\hline \multirow{3}{*}{ Treatment } & \multirow{3}{*}{$\begin{array}{l}\text { No. of } \\
\text { rats }\end{array}$} & \multicolumn{9}{|c|}{ Mammary response* } \\
\hline & & \multicolumn{4}{|c|}{ Duct system } & \multicolumn{5}{|c|}{ Alveolar system } \\
\hline & & - & \pm & + & H & I & II & III & IV & V \\
\hline Reserpine $(1 \mathrm{mg} / \mathrm{kg})$ & 10 & 0 & 0 & 0 & 10 & 0 & 0 & 0 & 3 & 7 \\
\hline Reserpine + Nialamide $(250 \mathrm{mg} / \mathrm{kg})^{* *}$ & 9 & 2 & 2 & 5 & 0 & 1 & 3 & 5 & 0 & 0 \\
\hline Reserpine + L-DOPA $(250 \mathrm{mg} / \mathrm{kg}) * * *$ & 5 & 5 & 0 & 0 & 0 & 4 & 1 & 0 & 0 & 0 \\
\hline Nialamide & 5 & 1 & 3 & 1 & 0 & 1 & 4 & 0 & 0 & 0 \\
\hline L-DOPA & 5 & 2 & 2 & 1 & 0 & 2 & 3 & 0 & 0 & 0 \\
\hline
\end{tabular}

*See Figure $1 \mathrm{I}-\mathrm{V}$ and notes of Table 1.

**Given 16-18 hr before reserpine.

$* * *$ Given one hour after reserpine.

1-III). The degree of the mammary lactogenic response to reserpine was apparently in correlation with the dose. The failure to induce a significant lactogenic response after administration of $0.1-0.25 \mathrm{mg} / \mathrm{kg}$ might be due to the inadequate doses. Neuroleptic effects of reserpine were also related to the dose. The rats treated with $0.75 \mathrm{mg} / \mathrm{kg}$ or $1.0 \mathrm{mg} / \mathrm{kg}$ reserpine showed the typical reserpine syndrome; arched back, lid ptosis and decreased motor activity. Lower dose $(0.25 \mathrm{mg} / \mathrm{kg})$ produced only a mild sedation.

Nialamide $(250 \mathrm{mg} / \mathrm{kg})$, a MAO-inhibitor, was administered 16-18 hours before the injection of reserpine $(1 \mathrm{mg} / \mathrm{kg})$, in order to determine whether the lactogenic effect of reserpine could be inhibited. Nialamide effectively reversed the action of reserpine, as can be seen in Table 2. A much clearer reversion was obtained by the injection of L-DOPA $(250 \mathrm{mg} / \mathrm{kg}$ ) one hour after the reserpine treatment. In this case, the development of ducts and alveoli was completely inhibited (Table 2). The histology was just comparable to that of the normal male controls. The rats given nialamide or L-DOPA in combination with reserpine did not develop the reserpine syndrome described above. Injection of nialamide or L-DOPA alone had no detectable influence on the mammary glands. One of the 10 rats injected with reserpine placebo alone showed a positive mammary lactogenic re- sponse (Table 1). This is somewhat puzzling because low doses of reserpine and L-DOPA dissolved or suspended in the same placebo did not bring about such lactogenic effect on the glands.

Body, testicular and pituitary weights were not markedly different between the control and the experimental animals. In rats treated with reserpine $(0.5-1.0 \mathrm{mg} / \mathrm{kg})$ adrenal weights were higher than in the controls, but were not significantly different from those of the rats treated with nialamide or L-DOPA in combination with reserpine.

\section{Discussion}

The present investigation could confirm earlier findings that single injections of reserpine stimulate prolactin secretion as evidenced by the induction of pseudopregnacy in rats (Barraclough and Sawyer, 1959; Coppola et al., 1965), although mammary lactogenic response is not the best measure of prolactin secretion. The participation of ACTH in this lactogenic effect cannot be excluded, because reserpine has been reported to stimulate the release of ACTH (see Gold and Ganong, 1967). The dosage of reserpine, $1 \mathrm{mg} / \mathrm{kg}$, found in the present experiments to give $100 \%$ positive lactogenic response in the male rats is just comparable to the dosage at which 
$100 \%$ of the female rats treated on the first day of diestrus resulted in pseudopregnancy (Barraclough and Sawyer, 1959). Meites et al. (1959) reported that daily injections of reserpine induced mammary gland growth and lactation in female rats after estrogen priming. In the present investigation it should be emphasized that mammary lactogenic reaction was achieved within 2 days by a single injection of reserpine in the male rat without any pretreatment or priming with estrogen.*

The fact that the lactogenic effect of reserpine could be inhibited by the treatment with a MAO-inhibitor (nialamide) and also by supplemental treatment with L-DOPA in the present experiments indicates that prolactin release following reserpine is due to the result of depletion of monoamines in the CNS, because the inhibition of MAO activity prevents the depletion of brain monoamines by reserpine and the treatment with L-DOPA, a precursor to dopamine and norepinephrine, replenishes the brain catecholamine levels following the depletion by reserpine (Matsuoka, 1964). Similar results were obtained by Coppola et al. (1965) and Van Maanen and Smelik (1968) in the studies of the inductive mechanisms of pseudopregnancy in rats. Mizuno et al. (1964) also reported that a MAOinhibitor (iproniazid) inhibited the lactational response to electrical stimulation of the uterine

\footnotetext{
* The sensitivity of the mammary glands of male rats to the hormones has been studied by several investigators (see, Lyon et al., 1955; Cowie and Folley, 1961). However, the results reported so far are conflicting. Ahrén and Etienne (1958) stated that there was no real difference between male and female mammary gland development with estrogen and other mammogenic hormones. Alveolar cyst formation with estrogen and progesterone was more often encountered in the male rats than in the females (Ahrén, 1959). In contrast, Neumann et al. (1966) recently reported that lactogenic response of the mammary gland to prolactincorticoid therapy (with estrogen-progesterone priming) was less marked in castrated male rats than both in castrated feminized (by cyproterone acetate) male and spayed female rats.
}

cervix in rats, but did not inhibit the mammary response produced by reserpine. A discrepancy between the results of Meites' laboratory and our own may be due to the difference in sex of the animals, the drugs used and the treatment schedules.

The lactogenic changes in the male mammary glands were found to be produced or blocked by the same pharmacologic treatments that had been reported to be effective in causing or preventing prolactin release in the female rat. This would suggest that similar mechanisms for prolactin release exist also in the male rat. The earlier findings that hypothalamic lesions (De Voe et al., 1965) and hypothalamic estrogen implantation (Deis, 1967) produce typical lactogenic reactions in the male mammary glands as they do in the females (McCann and Friedman, 1960; Ramirez and McCann, 1964) seem to reinforce this assumption. Therefore, it would be true that a tonic inhibitory control of the hypothalamus over prolactin secretion is preventing mammary gland development in normal males. The physiological significance of prolactin in the male is still unclear because the endocrinological environments in the male differ from those in the female.

\section{Acknowledgements}

We were supported by grants from the Ministry of Education of Japan. We express our hearty thanks to Dr. K. Kakeda, Professor of Neuropsychiatry, for his continued encouragement and valuable advices. For generous supplies of drugs, we are grateful to Torii Pharmaceutical Co. for special reserpine placebo, to Pfizer-Taito Co. (Tokyo) for nialamide and also to Kyowa Hakko Co. for L-DOPA.

\section{References}

Ahrén, K. (1959). Acta Endocrinol. 30, 435. Ahrén, K. and M. Etienne (1958). Ibid. 28, 89. Barraclough, C. A. and C. H. Sawyer (1959). Endocrinology 65, 563.

Coppola, J. A., R. G. Leonardi, W. Lipp- 
mann, J. W. Perrine and I. Ringler (1965) Ibid. 77, 485.

Cowie, A. T. and S. J. Folley, Sex and Internal Secretion. Young, W. C. (ed.) Williams \& Wilkins, Baltimore, p. 590 (1961).

Deis, R. P. (1967). Acta Physiol. Lat. Am. 17, 115.

De Voe, W. F., V. D. Ramirez and S. M. McCann (1965). Endocrinology 78, 158.

Everett, J. W. The Pituitary Gland. Harris, G. W. and Donovan, B. T. (eds.) Univ. Carifornia Press, Los Angeles, p. 166 (1966).

Gold, E. M. and W. F. Ganong Neuroendocrinology II. Martini, L. and Ganong, W. F. (eds.) Academic Press, N. Y., p. 377 (1967).

Kanematsu, S. Brain Function and Reproduction I. Kawakami, M. (ed.) Kyodoisho Shuppan, Tokyo, p. 99 (1968).

Lyon, W. R., R. E. Johnston, R. D. Cole and C. H. Li The hypophyseal Growth Hormone, Nature and Actions. Smith, R. W., Gaebler, O. H. and Long, C. N. H. (eds.) Blakiston, N. Y., (1955).

Matsuoka, M. (1964). Jap. J. Pharmacol. 14,
181.

McCann, S. M. and H. F. Friedman (1960). Endocrinology. 66, 217.

Meites, J. Proc. First Internat. Pharmacol. Meeting I. Guillemin, R. (ed.) Pergamon Press, Oxford, p. 151 (1962).

Meites, J. Neuroendocrinology I. Martini, L. and Ganong, W. F. (eds.) Academic Press, N. Y., p. 669 (1966).

Meites, J., C. S. Nicoll and P. K. Talwaker (1959). Proc. Soc. Exptl. Biol. Med. 101, 563.

Mizuno, H., P. K. Talwaker and J. Meites (1964). Ibid. 115, 604.

Neumann, F., W. Elger and R. von BerswordtWallrabe (1966). J. Endocrinol. 36, 353.

Ramirez, V. D. and S. M. McCann (1964). Endocrinology 75, 206.

Ratner, A., P. K. Talwaker and J. Meites (1965). Ibid. 77, 315.

Robinson, B. (1957). Med.J. Australia 44, 239.

Van Maanen, J. H. and P. G. Smelik (1968). Neuroendocrinology 3, 177.

Wilkins, L. W. (1954). Ann. N. Y. Acad. Sci. 59, 36.

Zeilmaker, G. H. (1963). Acta Endocrinol. 43, 246. 